\title{
On the Estimation of Elapsed Life of Oil-Immersed Power Transformers
}

\author{
Manoj Kumar Pradhan, Student Member, IEEE, and T. S. Ramu
}

\begin{abstract}
Inadvertent failure of power transformers has serious consequences on the system reliability, economics, and the revenue accrual. An accurate estimation of transformer life can, to a very large extent, mitigate the problems, besides satisfying the conflicting requirements of optimum utilization of the equipment and safeguarding the reliability.

In this endeavour, the authors have planned long duration aging experiments on scaled-down (prorated) models [1] of a transformer, incorporating all of the essential features of actual equipment under normal operating electric stress and accelerated thermal stress. In continuation of the authors' earlier experimental investigations, an elapsed life assessment study has been instituted by acquiring insulation-aging data under accelerated thermal stresses.
\end{abstract}

Index Terms - Carbon oxides, degree of polymerization, elapsed life, empirical model, furfurals, transformer insulation.

\section{NOMENCLATURE}

$K \quad$ Specific reaction rate.

$K_{0} \quad$ Frequency factor, defined in (1).

a...f Model coefficients in (9).

$\mathrm{A}_{g} \quad$ Degradation parameter, defined in (2).

AAF Accelerated aging factor.

$\mathrm{AAF}_{e q} \quad$ Equivalent accelerated aging factor.

AF 2-Acetylefuran dissolved in oil (in $\mu \mathrm{g} / \mathrm{kg}$ ).

BDVO Breakdown voltage of oil (in kilovolts).

BDVP Breakdown voltage of paper (in kilovolts).

$\mathrm{C}_{o} \quad$ Constant term in (9).

$c c_{i} \quad$ Correlation coefficients.

$\mathrm{CO}$ Carbon monoxide dissolved in oil (in ppm).

$\mathrm{CO}_{2} \quad$ Carbon dioxide dissolved in oil (in ppm).

$\mathrm{COx} \quad$ Carbon oxides $\left(\mathrm{CO}, \mathrm{CO}_{2}\right)$ dissolved in oil (in ppm).

DF Dissipation factor.

DGA Dissolved gas analysis.

DP Degree of polymerization.

DTCM Diagnostic testing and condition monitoring.

$\mathrm{E}_{a} \quad$ Activation energy of the aging process.

EOL End of life of power transformer.

FA Furfuryle Alcohol dissolved in oil (in $\mu \mathrm{g} / \mathrm{kg}$ ).

FD 2-Furaldehyde dissolved in oil (in $\mu \mathrm{g} / \mathrm{kg}$ ).

FTIR Fourier transform infrared detector.

GG Gas generation.

HM2F 5-Hydroxymethyle-2-Furfural dissolved in oil (in $\mu \mathrm{g} / \mathrm{kg})$.

Manuscript received June 23, 2004; revised October 18, 2004. Paper no. TPWRD-00293-2004.

The authors are with the Department of High Voltage Engineering, Indian Institute of Science, Bangalore 560012, India (e-mail: manoj@hve.iisc.ernet.in). Digital Object Identifier 10.1109/TPWRD.2005.848663
HPLC High-performance liquid chromatograph.

HST Hottest spot temperature (in degrees Celsius).

M2F 5-Methyle-2-Furfural dissolved in oil (in $\mu \mathrm{g} / \mathrm{kg}$ ).

OIP Oil-impregnated paper.

particle Micro particle count.

PD Partial discharge.

ppb Parts per billion.

$\mathrm{T} \quad$ Absolute temperature (in degree Kelvin).

TCG Total combustion gases dissolved in oil (in ppm).

TF Total Furan contents dissolved in oil (in $\mu \mathrm{g} / \mathrm{kg}$ ).

$\mathrm{w}_{i} \quad$ Normalized correlation coefficient (7).

\section{INTRODUCTION}

F AILURE of power transformers is among the more frequent causes of long interruptions in power supplies with serious repercussions on the system reliability, besides entailing loss of revenue. It is therefore essential to closely monitor the equipment in order to detect an impending failure in its formative stage. Implied in this procedure is the conduct of a series of well-planned diagnostic (noninvasive, nondestructive) tests, at appropriate intervals of time, to catalog the dynamics of degradation of electrical insulation thereof. This procedure of repetitive periodic testing of equipment insulation is called diagnostic testing and condition monitoring (DTCM).

Mineral oil-impregnated paper (OIP) is the insulation of choice in transformers. However, this system suffers degradation and catastrophic failure due to thermal, electrical, and to induced mechanical stresses. These stresses, singly and in combination, account for a rapid degradation of either phase of the insulating structure. Of the several properties used as indices of aging, the load induced temperature of the hottest spot (HST) is believed to give information on the loss of life of equipment. The thermal stress is generally considered as the single and perhaps the most important factor affecting the life of liquid-immersed power transformers. Empirical formulae [2], [3] were proposed to estimate the elapsed life based on the maximum winding temperature.

A major revision to the work reported earlier for studying the thermal aspects of transformer has now been evolved [4]. In this revision, the condition-based evaluation of the insulation system, supplemented by the CIGRE document [5], has been made based on the thermochemical reaction kinetics.

A relatively recent IEEE guide [6] prescribes the standard test procedure for thermal evaluation of liquid-immersed transformers. This document provides a method of estimating the maximum operating temperature (HST).

Among the more important byproducts of the processes leading to thermal degradation of OIP are carbon oxides ( $\mathrm{COx})$, 
a class of hydrocarbons including what are called furans. However, these compounds exist in both free state as well as in dissolved state. The extent to which the normal service life has been lost, also called the elapsed life of insulation, can to a certain extent, be discerned by detecting, identifying, and quantifying these byproducts. The physico-chemical behavior of OIP can be assessed with higher confidence by performing destructive testing viz. tensile strength, degree of polymerization. However, such tests and onsite measurements on power transformers in service are precluded. Therefore, one has to take recourse to laboratory-controlled experiments to try and extrapolate the results to full-size transformers onsite.

In the recent past, thermal aging experiments have been performed to study the gas generated and their rate of evolution. However, the experiments are only material centric, in that oilimpregnated paper samples are used as specimens and not a prorated transformer model [6] (appendix) [7]-[12]. Detection and quantification of furfural compounds and other gasses in the dissolved and in the free state, based on such experiments that could be correlated with DP, are not realistic. Further, a perusal of the literature in this area [13] shows that aspects in dissolved gas analysis (DGA) and high-performance liquid chromatograph (HPLC) for this purpose have been reported in great detail, but methods for estimating the life of the transformer using this data appear to be scanty.

Over the years, different criteria have been prescribed for the prediction of terminal or end of life (EOL) of equipment from the standpoint of its insulation. But thus far, no straightforward and unequivocal criterion is forthcoming. The formulations given by the IEEE and IEC guides for calculating probable life use temperature rise as the only index of aging. Results of such calculation seem to introduce large errors. It is needless to say that any conformal procedure proposed in the accurate prediction of EOL has to be based on a technically feasible and economically viable consideration.

In view of these incongruencies, the IEC, CIGRE, and IEEE special study committee on transformers has decided to revise the guides. In the backdrop of this scenario, many laboratories the world over, are making concerted efforts to mitigate the situation, and the authors have taken this opportunity to try and work out an empirical model for estimating the elapsed life of power transformers based on the diagnostic parameters.

\section{ON THE THERMO-CHEMICAL DEGRADATION OF PAPER INSULATION}

The cellulose paper insulation used in a transformer, is a polymer of glucose chains, which, when subjected to elevated temperatures in excess of about $130{ }^{\circ} \mathrm{C}$, undergoes continuous structural changes, whereby opening up the glucose rings. The byproducts of this reaction are free glucose molecules, moisture, $\mathrm{COx}$ and organic acids, besides a class of hydrocarbons called furans. This process is called pyrolysis. Other reactions, such as oxidative and hydrolytic processes, also take place.

The oxidative reaction depends on the nature of the oxidizing agent, its structure, and $\mathrm{pH}$ value. The hydroxyl groups present in the cellulose get oxidized to produce moisture and carbon oxides. Water and acid cleaves the glycosidic bond, eventually yields free glucose monomers, which further decomposes to a class of furans. It is believed that detection and measurement of these compounds, which are present in the oil phase in a dissolved state, singly or in combination, gives a reasonable indication of the quantitative degradation of paper.

The first-order reaction kinetics is expressed by the relationship

$$
K=K_{o} \exp \left(-\frac{E_{a}}{k T}\right)
$$

where $K$ is the specific reaction rate. The term $E_{a}$ is the activation energy of the reaction (assumed to be constant), in calories/mol, or $\mathrm{J} / \mathrm{mol}$ or electron volts. $k$ is Boltzmann gas constant is equal to $1.987 \mathrm{calories} / \mathrm{mol} / \mathrm{K}$ or $8.314 \mathrm{~J} / \mathrm{mol} / \mathrm{K}$, or electron volts $/{ }^{\circ} \mathrm{K} . T$ is the absolute temperature in degrees Kelvin. The term $K_{o}$ is the frequency factor, a quantity that is assumed to be constant; it depends on the number of collisions of the molecules reacting to produce chemical deterioration of the insulation.

\section{EXPERIMENTAL INVESTIGATION TO TRANSFORMER INSULATION}

As has already been mentioned earlier, not all of the required tests can be performed on a power transformer in service. Some of the tests are destructive in nature. Given that the results thereof are vital in arriving at a diagnostic and monitoring procedure for transformers in actual working conditions, laboratory experiments on prorated units are essential. Accordingly, scaled-down (prorated) models of actual power transformers designed in the authors' laboratory and fabricated by a local transformer manufacturer have been used in a carefully planned experimental study [1], [14]. Eight, identical units rated for 5-kVA, 220/5000-V, 50-Hz, one-phase, core-type transformers incorporating all of the essential features of a large transformer are fabricated.

All units are subjected to a similar stress environment. Provision has been made to sample free gas as well as for sampling oil (for DGA). The prorated units are rendered gas-tight by using self -sealing septum arrangement so as to avoid leakage either way. Measurement of the top, the middle, and the bottom oil temperature has been made using thermocouples. The HST was estimated using temperature-rise models [15], [16].

Thermal loading strategies need to be worked out carefully, keeping in view of the concept that the mechanism of aging under accelerated stress conditions shall remain invariant with normal operating conditions. A typical loading cycle is shown in Fig. 1. The loading blocks were adjusted such that the amount of aging during each block remains nearly the same and results in an experimental duration of about one year. Throughout the experimental run, the electrical stress was kept at normal levels (i.e., transformers were operated at rated voltage).

In a high-voltage high-power transformer, a careful consideration of the two phases, winding insulation (solid part), and the insulating (and cooling) liquid medium are to be considered as separate entities. Therefore, the specimen has been monitored during the load cycle (online) and after the each load cycle, a series of invasive and noninvasive diagnosis tests has been performed on both phases. 


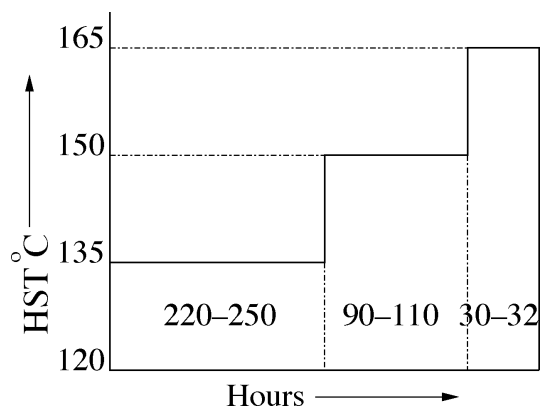

Fig. 1. Typical loading cycle.

\section{A. Monitoring Liquid Phase}

Top-oil, middle-oil, and bottom-oil temperature of the specimen have been continuously monitored during load cycle. Tests carried out on oil phase at the end of each load cycle include moisture content, capacitance, and dissipation factor $(\tan \delta)$, dielectric breakdown voltage, microparticle number density, detection, and measurement and quantification of the dissolved gases.

The deterioration of paper (cellulose) and oil (mineral) generate hydrocarbon gases that remain dissolved in transformer oil. Gases generated are hydrogen $\left(\mathrm{H}_{2}\right)$, carbon monoxide $(\mathrm{CO})$, carbon dioxide $\left(\mathrm{CO}_{2}\right)$, methane $\left(\mathrm{CH}_{4}\right)$, ethane $\left(\mathrm{C}_{2} \mathrm{H}_{6}\right)$, ethylene $\left(\mathrm{C}_{2} \mathrm{H}_{4}\right)$, acetylene $\left(\mathrm{C}_{2} \mathrm{H}_{2}\right)$, oxygen $\left(\mathrm{O}_{2}\right)$, and nitrogen $\left(N_{2}\right)$. The analysis of the gas phase dissolved in transformer oil to detect any possible fault(s) is called dissolved gas analysis.

Some of the furfurals are relatively stable in both free and in the dissolved state as has been pointed out earlier. The ASTM designation D 5837-99 standard procedure was followed in determining the furan compounds in oil. At higher temperatures, the gases from the nitrogen cushion of the transformer have been analyzed using a Fourier transform infrared (FTIR, Gasmet 00194 ) detector. In earlier stages of the aging experiments, a very large amount of 5-hydroxy-methyle-2-furfural has been detected. Only a small amount of 2-furaldehyde was also detected in gas cushion.

\section{B. Monitoring Solid Phase}

The number of glucose monomers present in a cellulose molecule per-unit chain length, the degree of polymerization (DP) as it is called is a dimensionless number between 1100 and 1200 in new (unaged) paper. The chain scission is a natural process accompanying degradation and decreases with duration of the service. This phenomenological event has a direct correlation with mechanical strength (tensile strength) of paper and is believed to be about the best and perhaps the most reliable indication of thermal aging.

The breakdown strength on aged paper sample was monitored along with certain PD quantities after every loading cycle. Contrary to expectations, these parameters remained little affected over the duration of the experiments.

\section{RESUlts of Aging EXPERIMENTS}

A number of properties have been identified as being reasonably sensitive indices of degradation and monitored contin-
TABLE I

Correlation of the Diagnostic Properties With DP

\begin{tabular}{|c|c|c|c|c|}
\hline \multirow{2}{*}{$\begin{array}{l}\text { SL } \\
\text { No. }\end{array}$} & \multirow[t]{2}{*}{ Property } & \multirow{2}{*}{$\begin{array}{c}\text { No. data } \\
\text { used }\end{array}$} & \multicolumn{2}{|c|}{ Correlation Coef. } \\
\hline & & & $c c_{i}$ & Remark \\
\hline 1 & $\mathrm{CO}$ & 40 & 0.79 & Fair \\
\hline 2 & $\mathrm{CO}_{2}$ & 40 & 0.74 & Fair \\
\hline 3 & $\mathrm{TCG}$ & 40 & 0.39 & Poor \\
\hline 4 & DF & 12 & 0.84 & $\dagger$ \\
\hline 5 & particle & 8 & 0.97 & $\dagger$ \\
\hline 6 & BDVO & 10 & 0.97 & $\dagger$ \\
\hline 7 & BDVP & 8 & 0.93 & $\dagger$ \\
\hline 8 & FD & 20 & 0.78 & Fair \\
\hline 9 & $\mathrm{TF}$ & 20 & 0.78 & Fair \\
\hline 10 & $\mathrm{AF}$ & 20 & 0.75 & Fair \\
\hline 11 & $\mathrm{M} 2 \mathrm{~F}$ & 20 & 0.75 & Fair \\
\hline 12 & $\mathrm{HM} 2 \mathrm{~F}$ & 20 & 0.17 & Very poor \\
\hline 13 & FA & 20 & 0.56 & Poor \\
\hline
\end{tabular}

$\dagger$ : Number of data sets are insufficient to make any comment.

uously. For the sake of brevity and succinctness, only the more important ones are included here. The correlation of various properties of insulation with DP have been shown in Table I.

A comparison has been made between the different properties with respect to their sensitivity to the amount of aging. In so doing, a term, " $A_{g}(i)$ " has been defined as the sum of the products of temperature $\left(\mathrm{HST}_{i}\right)$ and aging duration $\left(t_{i}\right)$ up to and including the block $i$

$$
A_{g}(i)=\sum_{i=1}^{i} \mathrm{HST}_{i} \times t_{i} .
$$

The term " $A_{g}$ " represents a quantitative index of thermal degradation or aging. In some sense, the quantity $A_{g}(\mathrm{i})$ can be treated as a measure of the amount of abstract degradation of insulation, the abstraction absolves itself into a measurable quantity when a property of insulation sensitive to the degradation is identified.

To facilitate making references and comparisons to field data, as also the results of other authors, a transformation of the quantity in (2) has been suggested, in which $A_{g}$ is expressed in terms of DP by way of a standalone program.

The changes in the DP versus duration of aging with the applied load cycle are shown in Fig. 2. It may be observed that the DP (mean) shows, as expected, a decreasing trend with the accumulation of degradation. In fact, toward the end, the DP can be seen to have come down to a value of about 200, which is already approaching the lower limit for acceptance.

\section{A. Carbon Oxides}

Transformers in service are monitored for dissolved gas content as this has shown promise of being effective in the diagnosis of particular fault types, such as arcing and PD, but the present knowledge appears to be insufficient [17], [18] to detect and analyze faults in paper insulation especially of thermal origin.

This aspect of dissolved gas analysis has been taken up rigorously in the present work. In the following, the efficacy of the gas analysis, based on COx and a class of the furfurals which are seen to bear a fair degree of correlation with the amount of degradation, are shown in Figs. 3-10.

It has been pointed out that the amount of generated gases and furfurals are on the higher side in the laboratory experiments 


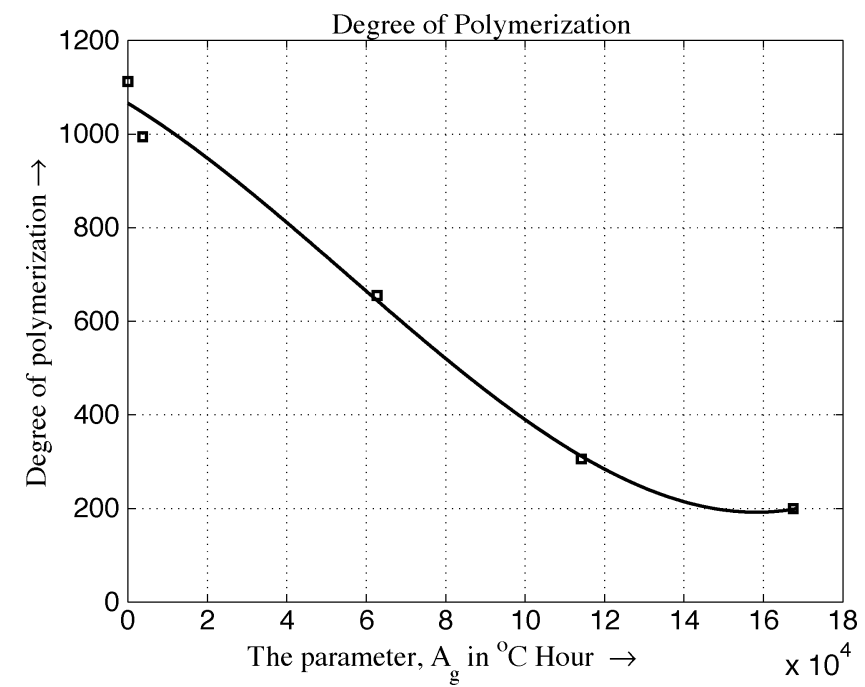

Fig. 2. Degree of polymerization versus $A_{g}$.

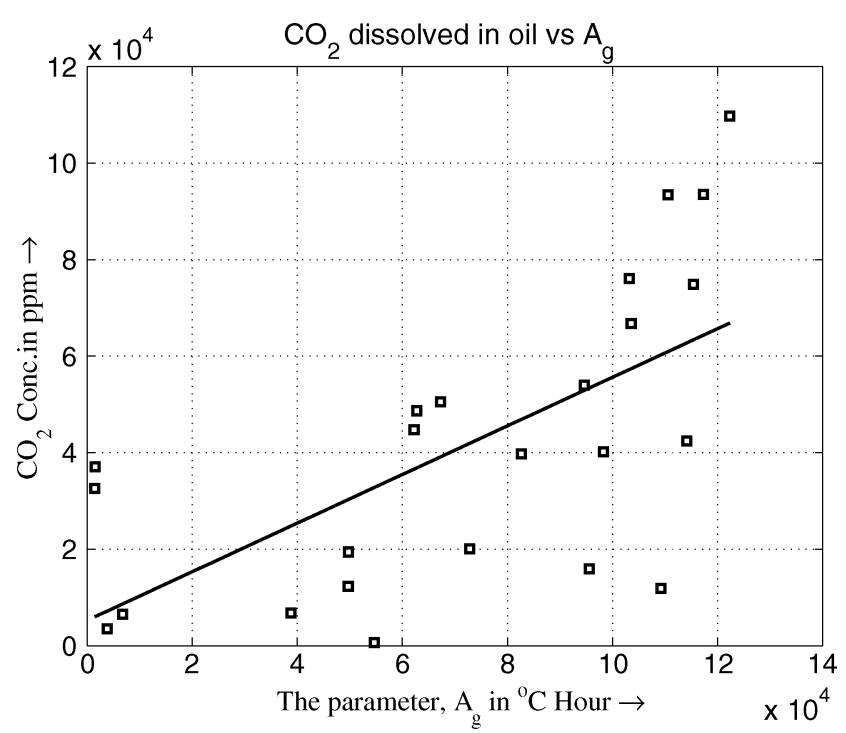

Fig. 3. Scatter in $\mathrm{CO}_{2}$.

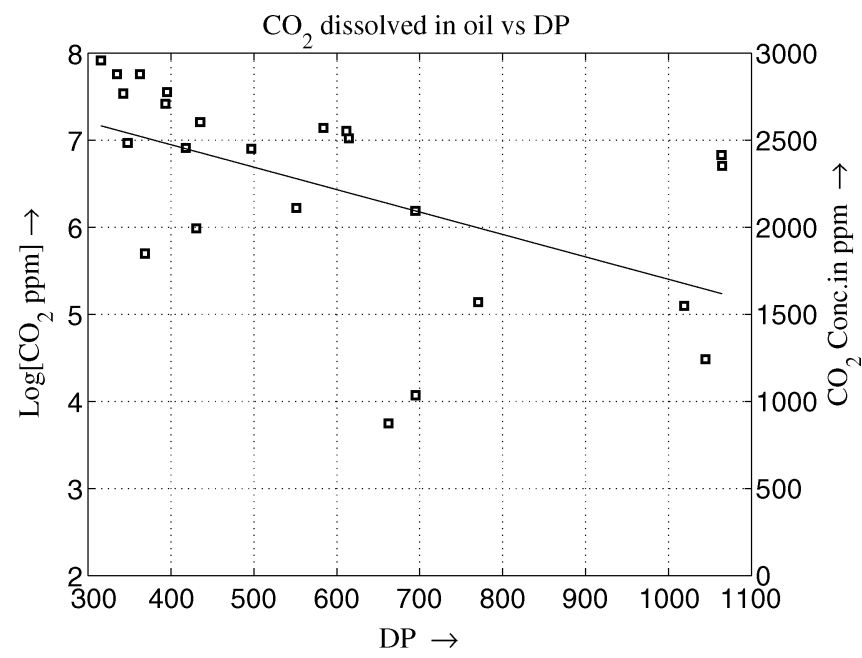

Fig. 4. $\mathrm{CO}_{2}$ versus DP.

[1], [8], [17] than in transformers in the field. An appropriate correction (presented later) has been given to validate the data

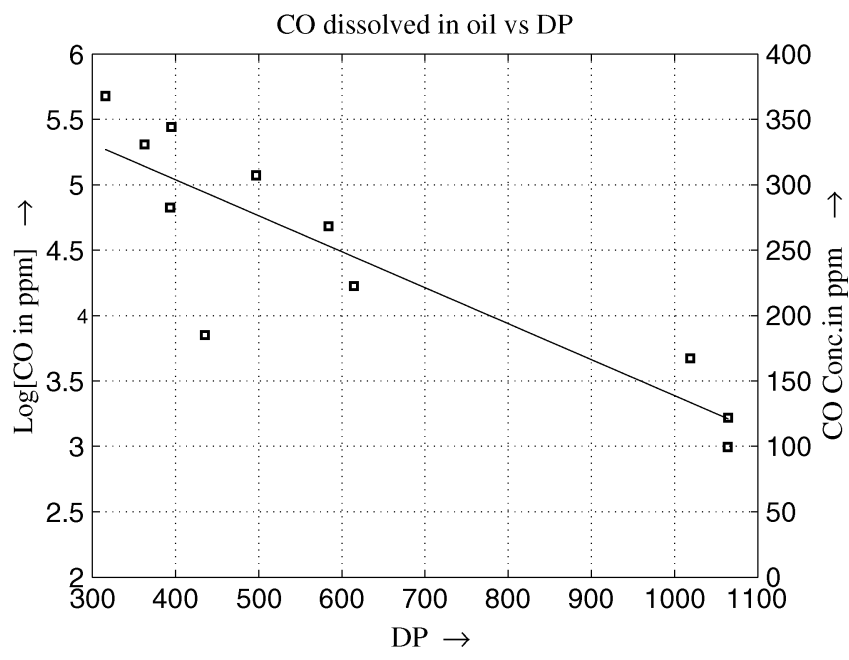

Fig. 5. CO versus DP.

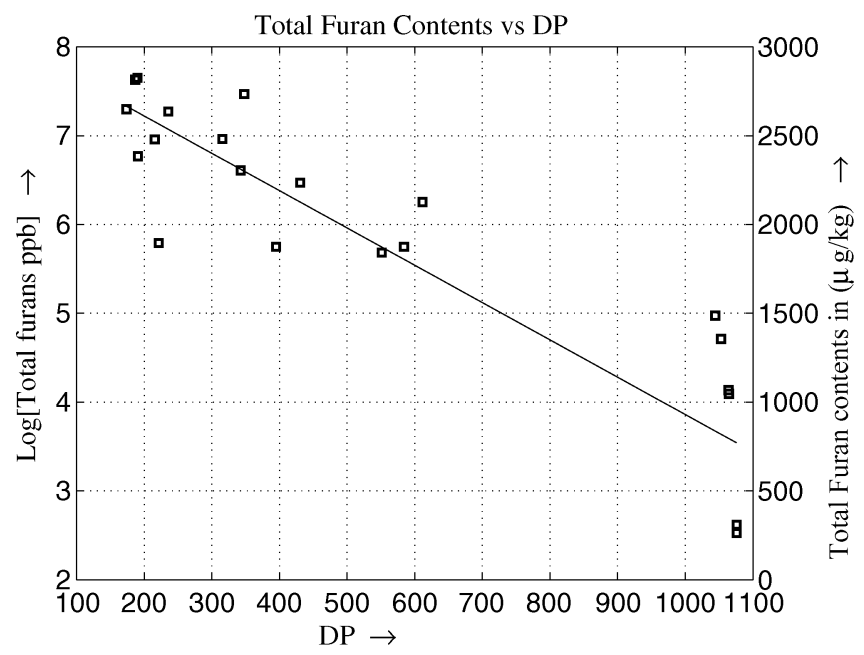

Fig. 6. Total furans dissolved in oil versus DP.

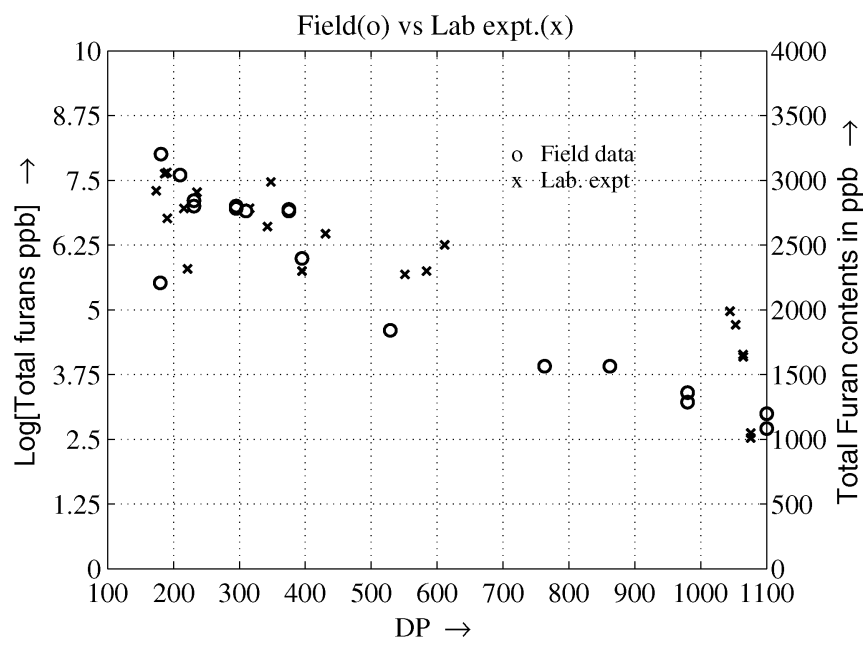

Fig. 7. Comparison with field data.

with an actual transformer onsite and corrected results have been presented.

It can be observed from Fig. 3 that the $\mathrm{CO}_{2}$ plot is scattered wrt the term " $A_{g}$ ". It is difficult to map the relationship between 


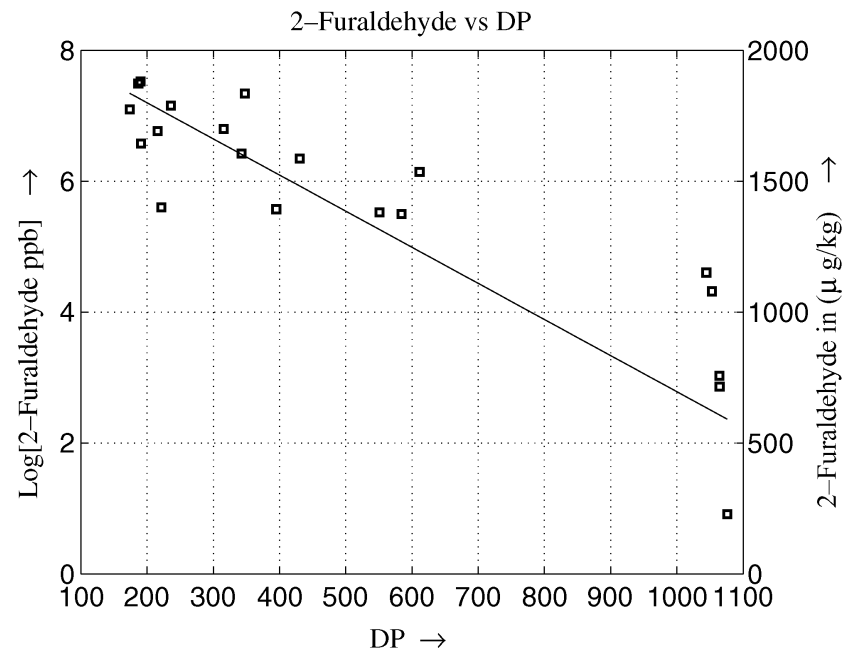

Fig. 8. The 2-furadehyde versus DP.

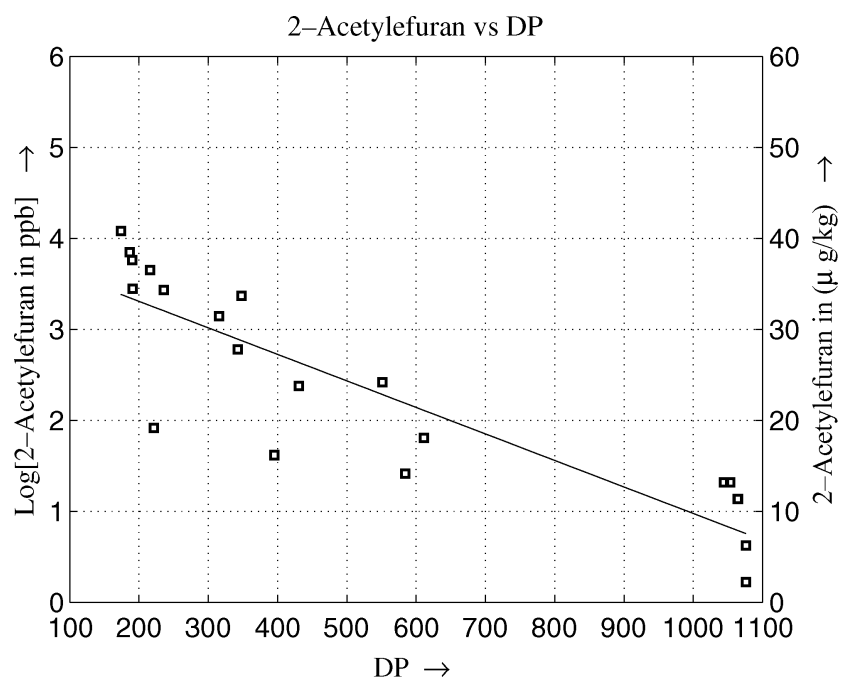

Fig. 9. The 2-acetylfuran versus DP.

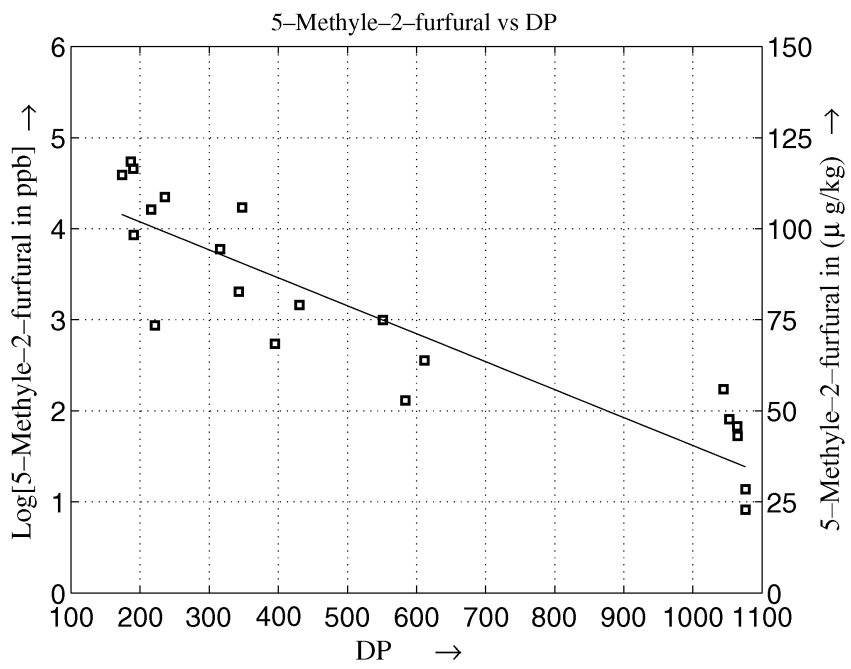

Fig. 10. The 5-methyl-2-furaldehyde versus DP.

degradation and $\mathrm{CO}_{2}$. However, it is seen that a linear curve can be fitted between the logarithm of gas generation and degradation data. Later, in this section, the logarithm of gas generation
(GG) has been plotted against the DP value and reference has been given to published literature wherever it is applicable. For the convenience and readability, the linear scale has been shown in the right $y$-axis of these plots.

It can be seen here that the logarithm of COx concentration (Fig. 4) is still scattered but a nearly linear relationship (trend) can be established between this parameter and DP. The variation of $\mathrm{CO}_{2}$ data obtained from the present experimental studies seems to be in line with field data [19]. Similar results can be observed in case of $\mathrm{CO}$ from Fig. 5.

\section{B. Furfural Analysis}

Of the five furfurals (Table I), a few of them have been seen to bear a fair correlation with DP. In Fig. 6, the changes in total furans (TF) content w.r.t. DP has been shown. It can be noted that though this parameter shows more or less monotonicity, it has been observed that [14] the data presented there have large variations from transformer to transformer.

In Fig. 7, a scatter plot of total furan content data acquired from the laboratory experiments as well as data on the power and station transformer in the field has been presented. It can be seen that the present experimental data have reasonable correlation with the actual field data.

The 2-Furaldehyde, an important degradation byproduct of cellulose, is known to indicate the loss of life of paper in the power transformer in service. This byproduct is the primary furfural and increases monotonically with aging. The data, however, are generally scattered and have been shown in Fig. 8.

It is interesting to note that the two other furfurals, 2-Acetylfuran and 5-Methyl-2-furaldehyde show unanticipated continuous change similar to 2-Furaldehyde, in all of the cases observed. The repeatability and reproducibility in the trends of these two furfurals can be seen in Figs. 9 and 10.

\section{ESTIMATION OF LIFE OF OIL-FILLED TRANSFORMERS}

In the recent past, expert systems for automatic monitoring of system performance with particular reference to station equipment have come into vogue. In such an endeavour, the thermal behavior of oil-impregnated cellulose and that of the oil component itself needed to be assessed. The long-time thermal behavior of such systems should be understood before any diagnostic schedules are to be drawn up. A failure model has been proposed by the CIGRE to study the serviceability of a power transformer and is shown in Fig. 11. It is imperative here that the actual measurement or estimation of these parameters will enable one to predict the remaining service life and serviceability of the equipment besides predicting the failure.

\section{A. On the Accelerating Factor}

An aspect of great interest and relevance for power-supply utilities is to try and quote the elapsed life or remaining life of station equipment, such as a power transformer. This task is, by no means easy as it involves conflicting requirements. Montsinger's rule [2] states that a life reduction of nearly $50 \%$ would occur for every $10^{\circ} \mathrm{C}$ rise in the temperature of insulation. This rule is now untenable since the quality of every component of transformer insulation is now much more superior than it was 


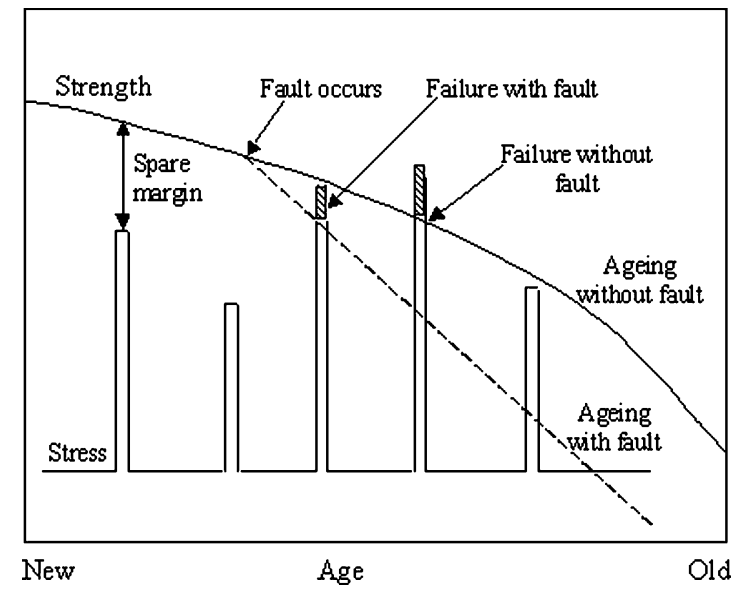

Fig. 11. Abstract of transformer failure-prepared by CIGRE.

at that time. A retrograde factor is the fact that the factors of safety on the insulation and other design components are much lower. This is due to the fact that the system is stressed, thermally, electrically, and mechanically to much higher levels.

The prediction of the remaining life of a transformer is based on the theory of stochastic processes (temporal random processes) and is quite outside the purview of the present investigation. However, a qualitative assessment of life can be made using empirical formulae suggested by Dakin. Essentially, it incorporates the HST in what is called an accelerated aging factor (3) which, when used as multiplication factor with the life spent in hours, gives elapsed life [4]

$$
\mathrm{AAF}=\operatorname{Exp}\left[\frac{15000}{383}-\frac{15000}{\mathrm{HST}+273}\right] .
$$

This factor, AAF, is nearly unity at a temperature of about $110^{\circ} \mathrm{C}$ and above this temperature, the factor accounts for thermal acceleration. If the hottest spot temperature varies due to a dynamic load cycle, the equivalent aging time can be calculated using (4)

$$
t_{\text {eqv-age }}=\sum \mathrm{AAF}_{\text {eqv }} \Delta t
$$

A factor defined as an "equivalent aging factor" can be worked out for relating stepped loading (Fig. 1) to continuous loading as shown below

$$
\mathrm{AAF}_{\mathrm{eqv}}=\frac{\sum_{i}^{N} \mathrm{AAF}_{i} \triangle t_{i}}{\sum_{i}^{N} \triangle t_{i}} .
$$

\section{B. Novel Approach to Estimation of Life Based on Diagnostic Properties}

The procedure for life estimation based on the formulation given above, though straightforward, does not seem to give an accurate estimation of life. The main reason for this is the fact that it considers temperature as the only degrading agent and ignores all other factors. It was mentioned earlier that the survey conducted by CIGRE reported that the uncertainty involved in
TABLE II

Mean Values of SeVeral Diagnostic Parameters AND DP

\begin{tabular}{c|c|c|c|c|c|c|c}
\hline \hline $\begin{array}{c}\text { Age } \\
\text { Years }\end{array}$ & $\begin{array}{c}\text { TF } \\
\text { ppb }\end{array}$ & $\begin{array}{c}\text { FD } \\
\text { ppb }\end{array}$ & $\begin{array}{c}\text { AF } \\
\text { ppb }\end{array}$ & $\begin{array}{c}\text { M2F } \\
\text { ppb }\end{array}$ & $\begin{array}{c}\text { CO } 2 \\
\text { ppm }\end{array}$ & $\begin{array}{c}\text { CO } \\
\text { ppm }\end{array}$ & DP \\
\hline \hline 1.27 & 41 & 13 & 2 & 4 & 218 & 34 & 1044 \\
2.55 & 54 & 19 & 2 & 5 & 265 & 40 & 971 \\
3.86 & 69 & 26 & 3 & 7 & 318 & 47 & 911 \\
5.21 & 88 & 36 & 4 & 8 & 381 & 55 & 853 \\
6.59 & 111 & 49 & 5 & 9 & 452 & 65 & 797 \\
8.01 & 139 & 66 & 5.6 & 11 & 533 & 75 & 744 \\
9.47 & 172 & 88 & 6.5 & 13 & 624 & 86 & 693 \\
10.97 & 212 & 115 & 7.5 & 15 & 726 & 98 & 644 \\
12.51 & 257 & 149 & 9 & 17 & 838 & 112 & 597 \\
14.09 & 310 & 191 & 10 & 20 & 960 & 126 & 553 \\
15.72 & 370 & 241 & 11 & 23 & 1093 & 142 & 511 \\
17.38 & 438 & 300 & 12 & 26 & 1236 & 158 & 471 \\
19.08 & 513 & 369 & 14 & 29 & 1388 & 176 & 433 \\
20.83 & 595 & 448 & 15 & 32 & 1548 & 194 & 398 \\
22.60 & 683 & 536 & 17 & 35 & 1714 & 212 & 365 \\
24.41 & 778 & 637 & 18 & 39 & 1884 & 231 & 334 \\
26.24 & 877 & 740 & 20 & 43 & 2058 & 250 & 306 \\
28.09 & 980 & 844 & 22 & 46 & 2231 & 269 & 279 \\
29.93 & 1084 & 950 & 23 & 50 & 2402 & 289 & 255 \\
31.76 & 1187 & 1060 & 25 & 53 & 2569 & 310 & 234 \\
33.55 & 1289 & 1180 & 26 & 56 & 2728 & 332 & 214 \\
35.27 & 1386 & 1310 & 28 & 60 & 2878 & 355 & 197 \\
\hline & & & & & &
\end{tabular}

the computation of loss of life based on Arrhenius law is high. This is due to the fact that the reactions rates are unpredictable within a factor of 3 to 4 . With this in view, the authors thought it fit to express the elapsed life, more precisely, in terms of the several chemical dissociation effects (decomposition byproducts of cellulose). Also, the degradation, being a stochastic process, is very imprecise if described by a mean process such as temperature rise only.

The mean values of some of the properties monitored during the series of experiments, including the DP, have been shown in Table II. The raw data have been corrected for thermal acceleration. For example, an acceleration factor in neighborhood of 40 seems to be a reasonable estimate [using (5)]. While on this point, the authors wish to point out that the correction factor would depend on the type of transformers such as hermetically sealed or free breathing type. Gas-liquid equilibrium considerations permit one to make a proper estimation of COx. If the diffusivity, solubility, and pressure of the gas are known, it is possible to find out its temperature-dependent equilibrium concentration.

It has been repeatedly established that DP bears an excellent correlation, very often greater than 0.9 , with aging. From Table I, the correlation of DP with the dissolved furan and COx is fair. Using these data as input, a linear, piece-wise continuous function has been evolved to relate the DP with the results of Furan and carbon oxides as in (9). Based on this model, a user-friendly software program has been developed. The objective of the program is to work out a computational algorithm for the approximate loss of the equipment life using the correlated diagnostic properties. Provision has been made in the software to estimate the DP without actually conducting this destructive experiment and using the DGA and furfurals data. The coefficients in this equation have been adjusted to read the same volumetric unit: either ppm or ppb. Since the sampling of oil can be done even when the transformer is in service, the formulation 
TABLE III

PARAMETERS OF THE PRoposed Model (9)

\begin{tabular}{c|c|c|c|c|c|c}
\hline \hline $\begin{array}{c}\text { Para- } \\
\text { meter }\end{array}$ & $c c_{i}$ & $w_{i}$ & $\begin{array}{c}\text { Normal } \\
\text { fitting }\end{array}$ & $\begin{array}{c}\text { Weighted } \\
\text { coef. }\end{array}$ & $\begin{array}{c}\text { Sym- } \\
\text { bol }\end{array}$ & $\begin{array}{c}\text { Range } \ddagger \\
(\mathrm{ppm} / \mathrm{ppb})\end{array}$ \\
\hline \hline Const. & - & - & 1897 & 1895 & $\mathbf{C}_{\mathbf{o}}$ & - \\
$\mathrm{CO}$ & 0.792 & 0.172 & -60.59 & -62.69 & $\mathbf{a}$ & $30-400$ \\
$\mathrm{CO}_{2}$ & 0.715 & 0.160 & -54.10 & -52.02 & $\mathbf{b}$ & $218-4000$ \\
$\mathrm{TF}$ & 0.782 & 0.170 & -39.67 & -40.53 & $\mathbf{c}$ & $40-1900$ \\
$\mathrm{FD}$ & 0.776 & 0.169 & -30.20 & -30.61 & $\mathbf{d}$ & $10-1700$ \\
$\mathrm{AF}$ & 0.752 & 0.164 & -57.18 & -56.17 & $\mathbf{e}$ & $2-32$ \\
$\mathrm{M} 2 \mathrm{~F}$ & 0.755 & 0.164 & -54.30 & -53.56 & $\mathbf{f}$ & $4-67$ \\
\hline \hline
\end{tabular}

†: COx are in ppm and furpurals in ppb

given below can be used for online monitoring of the remaining life

$$
\begin{aligned}
& D P=g_{1}(\mathrm{CO})=\hat{\mathbf{a}}_{\mathbf{0}}+\hat{\mathbf{a}}_{\mathbf{1}} \log (\mathrm{CO}) \\
& D P=g_{2}\left(\mathrm{CO}_{2}\right)=\hat{\mathbf{b}}_{\mathbf{0}}+\hat{\mathbf{b}}_{\mathbf{1}} \log \left(\mathrm{CO}_{2}\right) \\
& D P=g_{3}(\mathrm{TF})=\hat{\mathbf{c}}_{\mathbf{0}}+\hat{\mathbf{c}}_{\mathbf{1}} \log (\mathrm{TF}) \\
& D P=g_{4}(\mathrm{FD})=\hat{\mathbf{d}}_{\mathbf{0}}+\hat{\mathbf{d}}_{\mathbf{1}} \log (\mathrm{FD}) \\
& D P=g_{5}(\mathrm{AF})=\hat{\mathbf{e}}_{\mathbf{0}}+\hat{\mathbf{e}}_{\mathbf{1}} \log (\mathrm{AF}) \\
& D P=g_{6}(M 2 F)=\hat{\mathbf{f}}_{\mathbf{0}}+\hat{\mathbf{f}}_{\mathbf{1}} \log (M 2 F) .
\end{aligned}
$$

The empirical formulations for predicting DP from only one gas parameter are called local models. A more general fitting is obtained by combining these individual linear relationships by introducing a weight to individual expression in (6). The weights are estimated based on the correlation of the parameters with DP and as in (7), and the improved model (the weighted linear model as it may be called) is shown in (8)

$$
\begin{gathered}
w_{i}=\frac{c c_{i}}{\sum_{i=1}^{i=6} c c_{i}} \\
D P=\sum_{i=1}^{i=6} g_{i} w_{i} .
\end{gathered}
$$

In its fully expanded form, DP can be expressed as a function of all the gas and furfural concentration as shown below

$$
\begin{aligned}
& \mathrm{DP}= \mathbf{C}_{\mathbf{o}}+\mathbf{a} \log (\mathrm{CO})+\mathbf{b} \log \left(\mathrm{CO}_{2}\right)+\mathbf{c} \log (\mathrm{TF}) \\
&+\mathbf{d} \log (\mathrm{FD})+\mathbf{e} \log (A F)+\mathbf{f} \log (M 2 F) \\
& \mathbf{C}_{\mathbf{o}}= w_{1} \hat{\mathbf{a}}_{\mathbf{0}}+w_{2} \hat{\mathbf{b}}_{\mathbf{0}}+w_{3} \hat{\mathbf{c}}_{\mathbf{0}}+w_{4} \hat{\mathbf{d}}_{\mathbf{0}}+w_{5} \hat{\mathbf{e}}_{\mathbf{0}} \\
&+w_{6} \hat{\mathbf{f}}_{\mathbf{0}} \\
& \\
& \mathbf{a}=w_{1} \hat{\mathbf{a}}_{\mathbf{1}} \quad \mathbf{b}=w_{2} \hat{\mathbf{b}}_{\mathbf{1}} \\
& \mathbf{c}=w_{3} \hat{\mathbf{c}}_{\mathbf{1}} \quad \mathbf{d}=w_{4} \hat{\mathbf{d}}_{\mathbf{1}} \\
& \mathbf{e =}=w_{5} \hat{\mathbf{e}}_{\mathbf{1}} \quad \mathbf{f}=w_{6} \hat{\mathbf{f}}_{\mathbf{1}} .
\end{aligned}
$$

Table III incorporates the values of the coefficients and their weights

$$
\text { Elapsed Life }=20.5 \times \ln \left[\frac{1100}{\mathrm{DP}}\right] \text { in yr. }
$$

The empirical formula given in (12) is based on an initial value of mean DP of about 1100 , for a fresh transformer paper.
The authors wish to mention that the amount of data collected during the experimental run might not have been sufficient to undertake an intensive statistical analysis. Hence, an objective assessment of the variability in the coefficients, their confidence interval estimation, and, hence, the bounds on the estimated life cannot be worked out at this point in time. Even so, the expressions derived above and used on an as-is-where-is basis, seem to give some interesting results, prompting the authors to believe that this could be a starting point for a more rigorous formulation of equipment life.

\section{CONCLUSION}

- An improved thermal aging experimental design has been instituted so as to gather information on the status of insulation by diagnostic testing and condition monitoring.

- The results of a series of experiments performed to assess the condition of insulation as a function of time suggests that this work could, with further refinement and data, have great potential for working out a more precise DTCM schedule for power transformers in service.

- Of the several parameters monitored during aging experiments, only a few parameters that have a good correlation with DP have been selected and tabulated for easy reference.

- A semi-empirical expression has been developed to estimate the loss of life of power and the station transformer by analyzing gas content and furfural dissolved in oil without performing offline and destructive tests. This is believed to be very useful information to station engineers and utility managers.

\section{REFERENCES}

[1] M. K. Pradhan and T. S. Ramu, "Diagnostic testing of oil-impregnated paper insulation in pro-rated power transformers under accelerated stress," in Proc. Conf. Rec. IEEE Int. Symp. Electrical Insulation, Indianapolis, IN, Sep. 19-22, 2004, pp. 66-69.

[2] V. M. Montsinger, "Loading the transformers by temperature," AIEE Trans., vol. 49, pp. 776-792, 1930.

[3] T. W. Dakin, "Electrical insulation deterioration treated as a chemical reaction rate phenomenon," AIEE Trans., vol. 66, pp. 113-122, 1947.

[4] IEEE Loading Guide for Mineral Oil Immersed Transformer, C57.91.1995, pp. 1-55.

[5] Working Group 09, Study Committee 12, "Lifetime evaluation of transformers," Electra, no. 150, pp. 39-51, Oct. 1993.

[6] IEEE Standard Test Procedure for Thermal Evaluation Liquid-Immersed Distribution and Power Transformers.

[7] W. Yue, H. Zhixiao, and J. Zhang, "Expediating the cellulose aging evaluation and life prediction through degree of polymerization measurements," in Proc. 2nd Int. Conf. Properties Applications Dielectric Materials, vol. 1, Sep. 12-16, 1988, pp. 328-331.

[8] D. H. Shroff and A. W. Stannett, "A review of paper ageing in power transformer," Proc. Inst. Elect. Eng. C, vol. 132, no. 6, pp. 312-319, Nov. 1985.

[9] H. Yoshida, Y. Ishioka, T. Suzuki, T. Yanari, and T. Teranishi, "Degradation of insulating materials of transformer," IEEE Trans. Electr. Insul., vol. EI-22, no. 6, pp. 795-800, Dec. 1987.

[10] J. Unsworth and F. Mitchell, "Degradation of electrical insulating paper monitored with high performance liquid chromatography," IEEE Trans. Electr. Insul., vol. 25, no. 4, pp. 737-746, Aug. 1990.

[11] J. P. Percherancier and P. J. Vaurchex, "Fourier Transform Infrared (FT-IR) spectrometry to detect additives and contaminants in insulating oils," IEEE Electr. Insul. Mag., vol. 14, no. 3, pp. 23-29, May/Jun. 1998. 
[12] R. M. Morais, W. A. Mannheimer, M. Carballeira, and J. C. Noualhaguet, "Furfural analysis for assessing degradation of thermally upgraded papers in transformer insulation," IEEE Trans. Dielectr. Electr. Insul., vol. 6, no. 2, pp. 159-163, Apr. 1999.

[13] A. M. Emsley, X. Xiao, R. J. Heywood, and M. Ali, "Degradation of cellulosic insulation in power transformers, part 2: formation of furan products in insulating oil," Proc. Inst. Elect. Eng., Sci. Meas. Technol., vol. 147, no. 3, pp. 110-114, 2000.

[14] M. K. Pradhan, "Conformal Thermal Models for Optimal Loading and Elapsed Life Estimation of Power Transformers," Ph.D. dissertation, Dept. High Voltage Eng., Indian Inst. Sci., Bangalore, India, Aug. 2004.

[15] M. K. Pradhan and T. S. Ramu, "Prediction of Hottest Spot Temperature (HST) in power and station transformers," IEEE Trans. Power Del., vol. 18 , no. 4, pp. 1275-1283, Oct. 2003.

[16] - "Estimation of the Hottest Spot Temperature (HST) in power transformers considering thermal inhomogeniety of the windings," IEEE Trans. Power Del., vol. 19, no. 4, pp. 1704-1712, Oct. 2004.

[17] H. Kan, T. Miyamoto, Y. Makino, S. Mamba, and T. Hara, "Absorption of $\mathrm{CO}_{2}$ and $\mathrm{CO}$ gases and furfural in insulating oil into paper insulation in oil-immersed transformers," in Proc. Conf. Rec. IEEE Int. Symp. Electrical Insulation, Pittsburgh, PA, Jun. 5-8, 1994, pp. 41-44.

[18] H. Kan and T. Miyamoto, "Proposals for improvement in transformer diagnosis using Dissolved Gas Analysis (DGA)," IEEE Electr. Insul. Mag., vol. 11, no. 6, pp. 15-21, Nov./Dec. 1995.

[19] D. Allan, C. Jones, and B. Sharp, "Studies of the condition of insulation in aged power transformers. Part 1: insulation condition and remnant life assessments for in-service units," in Proc. 3rd Int. Conf. Properties Applications Dielectric Materials, Tokyo, Japan, Jul. 8-12, 1991, pp. 1116-1119.

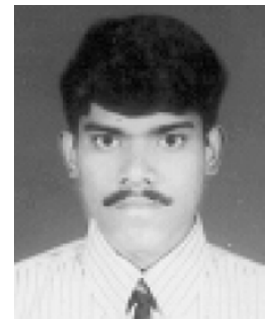

Manoj Kumar Pradhan (S'03) was born in Balasore, Orissa, in 1978. He received the B.E. degree in electrical engineering from the University College of Engineering (UCE), Burla, Orissa, in 2000. He received the M.Sc. (Eng.) and Ph.D. degrees from the Indian Institute of Science, Bangalore, in 2002 and 2005, respectively.

Currently, he is with the Department of Electrical Engineering, Indian Institute of Technology, Madras.

His research interests include condition monitoring of power equipment, application of $\mathrm{AI}$ techniques for fault diagnosis in power systems, and cryogenic insulation for superconductivity applications.

T. S. Ramu was born in Bangalore, India. He received the B.E. degree from Mysore University, Bangalore, India, the M.E. degree from the Indian Institute of Science, Bangalore, and the Ph.D. degree from IIT Madras, Madras, India.

Currently, he is a Professor in the Department of High Voltage Engineering, Indian Institute of Science. 